\title{
Wage Inequality on the Hungarian Labour Market: Technological Change, Expansion in Higher Education and the Role of the Minimum Wage*
}

\author{
Álmos Telegdy
}

The paper examines the development of wage inequality in Hungary between 1994 and 2016, based on the theories that explain the labour market impact of information and communication technologies (ICT). The analysis is based on the Hungarian Wage Survey Database and uses the empirical methods in the literature to calculate the change of the employment shares and wages of various jobs. As in most countries, the Hungarian labour market became polarized, but this has not been accompanied with wage polarization. Rather, the increase of wages was inversely proportional with skill. The paper proposes two reasons for this behaviour: one is the large increase in the minimum wage, while the other the educational expansion which increased the labour supply of highly skilled workers.

Journal of Economic Literature (JEL) codes: J31, J61, D31, R11

Keywords: wage inequality, wage dynamics, labour market polarisation

"Labor will become less and less important... More and more workers will be replaced by machines. I do not see that new industries can employ everybody who wants a job." (Wassily Leontief ${ }^{1}$ )

\section{Introduction}

Even though the Nobel laureate economist Leontief's prediction regarding the labour market took thirty years to materialise, something changed on the labour market in the early 1980s, and wage inequality started growing in most advanced countries. It was first documented in the US that between 1980 and 2009 high-

\footnotetext{
* The papers in this issue contain the views of the authors which are not necessarily the same as the official views of the Magyar Nemzeti Bank.

Álmos Telegdy is a Senior Economic Research Expert at the Magyar Nemzeti Bank. E-mail: telegdya@mnb.hu The paper is a revised version of the chapter "Effects of technological change on the labour market" of the Magyar Nemzeti Bank's Growth Report (2017). The paper benefited from the comments of András Balatoni, Péter Gábriel and János Köllő, and the participants of the Szirák Labour Market Conference (2017). The study contains the views of the author alone, and not the Magyar Nemzeti Bank. Any mistakes are the author's own.

The Hungarian manuscript was received on 27 March 2018.
}

DOI: http://doi.org/10.25201/FER.17.3.528

1 "Machines and Man", Scientific American, 1952, cited by Acemoglu and Restrepo 2016:1, http://www.nber. org/papers/w23285.pdf 
wage workers' earnings increased much more than that of medium- and lowwage workers. The difference between the most highly skilled and the least skilled workers was dramatic: while the real wages of college or university graduates grew by around 60 per cent, those without a high school diploma saw a decrease in their wages in real terms (Acemoglu-Autor 2011). This surprised researchers and policymakers because inequality had been on the decline for a long time before that. Goldin and Katz (2008) use long time series to document that wage inequality in the United States exhibited a downward trend between the early 20th century and the 1970s. Wage inequality rose not only in the United States. Katz and Autor (1999) document the wage differences between low- and high-wage workers in 16 developed countries and conclude that inequality has mostly increased, although much less than measured in the United States.

An analysis of the changes in the past 30 years by occupation shows that there is a more complicated relationship between qualifications and wage growth than a simple linear correlation. Researchers have shown in several countries that the occupations that were in the upper or lower segment of the wage distribution in 1980 based on their average wage enjoyed much larger wage growth until 2005 than medium-wage occupations. ${ }^{2}$ In parallel with the change in wages, the employment share of occupations also changed: high- or low-skilled jobs are increasingly present on the labour market, while the share of jobs that are traditionally performed by medium-skilled workers are on the decline.

This paper presents the theories that provide the most likely explanation for this major change. These attribute this significant reallocation on the labour market to the impact of information and communications technologies (ICT). The second half of the study documents the trends in wage inequality in Hungary during the previous two decades. This analysis is based on the Wage Survey Database that contains annual information from the early 1990s up until 2016 on the occupation, wage and other demographic features of Hungarian employees. Empirical methods from the literature are used to calculate how wages have changed across the various qualification and employment groups and document the increasing prominence or diminishing weight of employment groups on the labour market.

The results indicate that there are substantial differences in terms of labour market developments between the first half of the 1990s and the subsequent period. In the 1990s, high wages increased more than medium and low wages, and the share of high-skilled workers on the labour market dropped, probably due to the insufficient supply of graduate workers. By contrast, in the 2000s, labour market polarisation emerged: the proportion of the occupations with an average wage declined relative

\footnotetext{
${ }^{2}$ See the paper by Autor and Dorn (2013) on the United States, Goos et al. (2009) on 16 European countries and the World Bank (2016) on several developing countries.
} 
to those with low and high wages. However, wages did not follow this trend, as the wage growth of occupations was inversely proportional to the initial wage level since the early 2000s. Therefore, wage inequality increased between 1994 and 2000 , but there was a turnaround at the turn of the century, and inequality started to decrease. According to the calculations, in 2015 the wage difference between college or university graduates and those with at most a secondary school diploma was the same as in 1994.

Two changes can explain the drop in wage inequality. One is the minimum wage, which was substantially increased in 2001 and 2012, and boosted low wages. The second is the expansion in higher education, which bore fruit in 2000 and considerably increased the proportion of university and college graduates on the labour market. The first phenomenon raised low wages, while the second moderated the rise of high wages.

The next chapter presents the theories that explain the impact of ICT on the labour market. Chapter 3 describes the database, and Chapter 4 details the analysis. Chapter 5 then attempts to provide some explanations as to why Hungary has different wage dynamics than the advanced economies. The analysis ends with a summary of the results.

\section{Theoretical framework}

Economic theory needs to explain two interrelated phenomena. Data from developed countries show that wage inequality started increasing in the 1980s such that better educated workers received larger premia. Later, typically in the 1990s, the labour market became polarised, i.e. the relative size and wages of both high- and low-paying occupations increased at a higher rate than of averagepaying jobs. This chapter outlines the two theories that provide a simple market explanation for the two labour market developments.

\subsection{Tinbergen's race between education and technology ${ }^{3}$}

Wage changes are usually addressed in terms of employees' educational attainment on the basis of Tinbergen's (1974) model, which was first used by Katz and Murphy (1992) to explain the changes that took place in the 1980s. The model distinguishes two types of workers: the unskilled (those with at most a secondary school diploma) and the skilled (college or university graduates). The wage difference between the skilled and the unskilled is explained by the relative supply and demand of the two categories. The key assumption is that the two types of workers are imperfect substitutes in the production process. This is not an unrealistic hypothesis. Highskilled and low-skilled employees are employed together in firms, and at the level

\footnotetext{
${ }^{3}$ This chapter is based on a paper by Acemoglu and Autor (2011).
} 
of the national economy a high-skilled employee needs various products and services for work, which are provided by secondary school graduates. Production is described by a constant elasticity of substitution (CES) production function, where the two factors are the amounts of skilled and unskilled labour:

$$
Y=\left[\left(A_{1} N_{1}\right)^{(\sigma-1) / \sigma}+\left(A_{2} N_{2}\right)^{(\sigma-1) / \sigma}\right]^{\sigma /(\sigma-1)} .
$$

In the expression above, the number of skilled (unskilled) workers is $N_{1}\left(N_{2}\right) . A_{1}$ and $A_{2}$ are technological parameters influencing the productivity of the factors, and $\sigma$ is the elasticity of substitution between the two types of workers measuring how the change in relative wages influences the relative demand for the factors.

The wage premium of skilled workers rises if a technology is introduced that increases graduate employees' productivity (e.g. a computer will make a designer much more efficient than a machine operator). It will do so because the new technology and skilled employees are complements in the production process, therefore the productivity of skilled workers $\left(A_{1}\right)$ increases (relative to the unskilled). This relative wage growth expands the graduate wage premium. Assuming that workers' wage equals their marginal product, the derivative of Expression (1) with respect to $N_{1}$ and $N_{2}$ yields the following relative wage equation:

$$
\log \left(w_{1} / w_{2}\right)=(\sigma-1) / \sigma \log \left(A_{1} / A_{2}\right)-1 / \sigma \log \left(N_{1} / N_{2}\right) .
$$

In Expression (2), two factors influence the relative wage. The first is technology: if, for example, $A_{1}$ is greater than $A_{2}$, technology increases the productivity of skilled workers more than in the case of the unskilled. This boosts companies' demand for skilled workers, which lifts relative wages if $\sigma>1$ (i.e. skilled and the unskilled workers are imperfect substitutes). From the supply side, the relative number of graduate workers decreases the wage premium, and the elasticity between relative wages and the relative number of workers equals the inverse of the elasticity of substitution. This generates the race between education and technological change. Educational expansion decreases, while advances in technology increase the wage difference between the skilled and the unskilled. If an economy is characterised by an expansion in higher education (as was the case in developed countries and the whole of Europe), the supply of graduate employees increases, which in turn hinders their wage growth. It follows from this that if production processes had remained unchanged, the steady increase in the supply of high-skilled employees should have caused the university wage premium to fall. As the very opposite happened, it is likely that technological change triggered far more substantial changes on the labour market in favour of skilled workers than what could have been counterbalanced by the expansion in higher education. 


\subsection{Labour market polarisation}

The model discussed in the previous subchapter uses simple changes in supply and demand to provide an explanation for the increased wage inequality in the past decades and gives good predictions for the changes that occurred on the labour markets of developed countries in the 1980s. However, it cannot explain the labour market polarisation that has been happening since the 1990s, i.e. that occupations requiring average skills (typically jobs for factory workers) are losing ground to the occupations that involve low skills (mostly jobs in services performed by workers with at most a secondary school diploma) or high skills (which usually require a college or university degree).

Autor and Dorn (2013) supplement Tinbergen's theory to interpret labour market polarisation. To do so, they classify labour not only by skills but also by the type of tasks workers perform. The previous model's skilled-unskilled categorisation is expanded by dividing unskilled workers into two groups by the nature of their jobs, i.e. based on the amount of their routine tasks. In this context, a "routine task" will not be defined as one that is easy to carry out, but as one that can be broken down into steps that always need to be carried out in the same way and is repeated over time. The tasks of a factory worker recur often; similarly, an accountant's work is also repetitive and bound by well-defined rules. By contrast, a hairdresser or a cleaner (and many other people working in the service sector) encounter a different situation each time, although their work requires less expertise than that of a factory worker or an accountant. The tasks performed by such workers require either complex communication skills (e.g. in the case of a hairdresser or a beautician), or the recognition of complex, constantly changing patterns (e.g. a cleaner cleans rooms of various shapes and furniture). Those working in the service sector are generally found at the bottom of wage distribution, those in occupations comprising routine tasks in the middle, and graduate employees at the top.

Labour market changes are once again triggered by the impact of technology. Jobs requiring a degree are generally made more efficient as a result of ICT because they complement it in production: rapid communication and huge databases increase the efficiency of the work of managers, engineers and analysts. As ICT can perform repetitive routine tasks that are subject to rules, it can substitute routine workers and so the share of occupations carrying out such tasks is decreasing as ICT is becoming increasingly cheap. The tasks of those in the service sector are usually impossible to robotise, or only at a high cost. ICT has only recently become able to engage in effective communication and identify complex patterns (Brynjolfsson McAfee 2014), therefore the productivity of low-skilled workers in services has not been affected directly by the introduction of ICT, and thus the new technology has 
also had no direct impact on their wages. ${ }^{4}$ However, these workers are not shielded from indirect labour market consequences. Since the people carrying out routine tasks are increasingly losing their jobs and are not skilled enough for graduate jobs, they also look for jobs in the lower segment of the labour market, thereby competing with employees who have already been providing services. However, this effect is counterbalanced by the increased demand for services, which is generated by high graduate wages and the fact that the prices of some products are falling (as they can be produced cheaper with ICT). Some of the additional income is spent on the services market, which produces a scale effect, increasing the demand for unskilled workers.

To summarize, two developments result from the spread of ICT. Robots are crowding out medium-skilled workers carrying out routine tasks (who tend to work in manufacturing or offices). In turn, increased productivity generates additional income, boosting demand for services and, consequently, the labour demand for the employees who provide those services. As the wages of skilled labour increase (since their skills complement the new technology well), the labour market becomes polarised: demand for both high-skilled and low-skilled workers increases, which entails a rise in their wages. By contrast, the share of employees carrying out routine tasks in the middle of the wage distribution decreases on the labour market, which also affects their wages.

\subsection{Alternative explanations}

Besides the spread of ICT, there are alternative explanations for the large increase in wage inequality. According to one, the answer lies in the changes to the labour market's institutional system. The clout of two major labour market institutions protecting workers in the United States has diminished: the minimum wage plunged, and the role of trade unions has weakened (Card-DiNardo 2002). These institutions could be truly important in the convergence of low wages; therefore, they may influence wage distribution. However, the labour market institutions have not changed in all countries, but wage inequality has grown everywhere.

The other explanation is the growing volume of trade between developing and developed countries, which triggers similar mechanisms in wage setting, i.e. it poaches the jobs from medium-skilled factory workers, and their wages become

\footnotetext{
${ }^{4}$ This will not be the case in the future because ICT will increasingly filter into the service market (see, for example, the rise of self-driving cars in recent years). ICT is likely to transform the whole labour market in the near future, and it is unclear how this realignment will end. Depending on the assumptions, there are different estimates about the percentage of jobs performed by robots in the future. The World Bank puts this figure at 57 per cent in 20 years (World Bank 2016), while Arntz et al. (2016) believe it to be merely 9 per cent.
} 
lower as a result of the drop in demand. ${ }^{5}$ However, Baldwin (2016) shows that this could not have taken place without advanced communication technologies. In other words, globalisation is also being driven by technological change. Moreover, the share of medium-skilled workers also decreased in relative terms on the labour markets of developing, heavily exporting countries (World Bank 2016).

\section{Data}

This paper uses the Wage Survey Database compiled by the Hungarian National Employment Office. The analysis only considers the wages of employees in firms, because public sector wages are not directly determined by labour market supply and demand. The database provides information on the age, gender, educational attainment, occupation and wages of corporate employees. The analysis covers the period between 1994 and 2016, ${ }^{6}$ and the sample includes businesses employing at least 20 people. ${ }^{7}$ The companies had to complete the survey for blue collar workers born on the 5th and 15th, and for white collar workers born on the 5th, 15th and 25th of any month. If nobody at the company was born on these dates, the firm was dropped from the sample for the given year. In 2002, the threshold under which companies had to provide data for all their workers was raised to 50. Since 2011, workers in a public work scheme can be distinguished in the database. As their wage is regulated by law, they are not included in the analysis.

The database provides information on the total number of blue and white collar workers at the company level, which was used to produce weights in order to offset the sampling differences between blue and which collar workers within the firm.

Wage is measured by the monthly wage paid in May, which includes the base salary, overtime pay, other regular pay (e.g. language allowance, management allowance) but does not include non-regular income. This item is measured by $1 / 12$ th of the non-regular pay from the previous year and is added to the wages in May. Nominal wages are deflated with the consumer price index. The occupations are reported based on the Hungarian Standard Classification of Occupations (FEOR), which follows the ISCO categorisation developed by the International Labour Organization. ${ }^{8}$ The analysis uses 3-digit ISCO groups.

\footnotetext{
${ }^{5}$ Autor et al. (2013) find that in the US manufacturing employment has fallen to a greater extent in regions that were exposed to Chinese imports, and that the competition created by foreign trade is responsible for a quarter of the redundancies in manufacturing.

${ }^{6}$ Although the data are available since 1992, the first two years are not used because it would be very difficult to separate the effects of labour market liberalisation and the new technologies in the first turbulent years of the economic transition.

${ }^{7}$ In 1998, the database was supplemented with a random sample of smaller enterprises, but they are not included in this analysis to eliminate the effects of sample change.

${ }^{8}$ The classification of occupations changed in 2011, and the analysis harmonises the FEOR-93 (ISCO-88) and the FEOR-08 (ISCO-08) classification systems.
} 
Table 1 shows the number of observations as well as the total population (which consists of the weighted sum of the sample). In the 1990s, the data have information on about $90,000-100,000$ workers. In the 2000 s, this figure increases to $110,000-$ 130,000 , or even higher $(150,000-165,000)$ in certain years. Weighted figures are more stable at 1.2 million workers, with the exception of the first two years of the analysis, where the weighted number of elements is around 1.6 million.

\section{Table 1}

\section{Number of observations}

\begin{tabular}{|c|c|c|}
\hline Year & Sample & Population \\
\hline 1994 & 110,839 & $1,614,968$ \\
\hline 1995 & 109,885 & $1,583,435$ \\
\hline 1996 & 92,334 & $1,269,581$ \\
\hline 1997 & 91,422 & $1,229,928$ \\
\hline 1998 & 90,915 & $1,224,671$ \\
\hline 1999 & 89,044 & $1,169,112$ \\
\hline 2000 & 95,003 & $1,183,126$ \\
\hline 2001 & 91,224 & $1,108,623$ \\
\hline 2002 & 108,273 & $1,225,899$ \\
\hline 2003 & 112,525 & $1,213,671$ \\
\hline 2004 & 124,797 & $1,252,526$ \\
\hline 2005 & 132,884 & $1,257,645$ \\
\hline 2006 & 154,610 & $1,415,760$ \\
\hline 2007 & 132,412 & $1,251,285$ \\
\hline 2008 & 137,527 & $1,237,964$ \\
\hline 2009 & 129,569 & $1,223,417$ \\
\hline 2010 & 132,488 & $1,257,558$ \\
\hline 2011 & 119,460 & $1,208,077$ \\
\hline 2012 & 135,791 & $1,199,017$ \\
\hline 2013 & 126,907 & $1,199,639$ \\
\hline 2014 & 130,106 & $1,190,233$ \\
\hline 2015 & 165,768 & $1,164,694$ \\
\hline 2016 & 143,654 & $1,235,613$ \\
\hline
\end{tabular}

Note: The table shows the weighted and the unweighted number of elements in the sample. Population: the individuals employed by companies with at least 20 workers and using double-entry bookkeeping. 


\section{The evolution of wages and wage inequality in Hungary}

Now we turn to the examination of the Hungarian labour market and show how wages changed in the past 20 years. First, we present the dynamics of wages and then we turn to testing whether the labour market has become polarised in Hungary as elsewhere. The end of the chapter seeks to provide answers to the phenomena described below.

\subsection{Wage dynamics, 1994-2016}

Figure 1 shows the annual growth rate of wages for three skill groups (those without a secondary school diploma, secondary school graduates and college and university graduates). ${ }^{9}$ In the period studied, the wages of the low- and high-skilled increased at a similar pace, while those of the medium-skilled somewhat lagged behind. Wages increased steadily between 1995 and 2007, then stagnated for quite a few years on account of the crisis, and started growing again in the last years of the period. The wage advantage of university graduates was achieved until 2000. The wage growth was similar in the other two educational groups until 2009 when the wages of the low-skilled became persistently higher than those with a high school diploma.

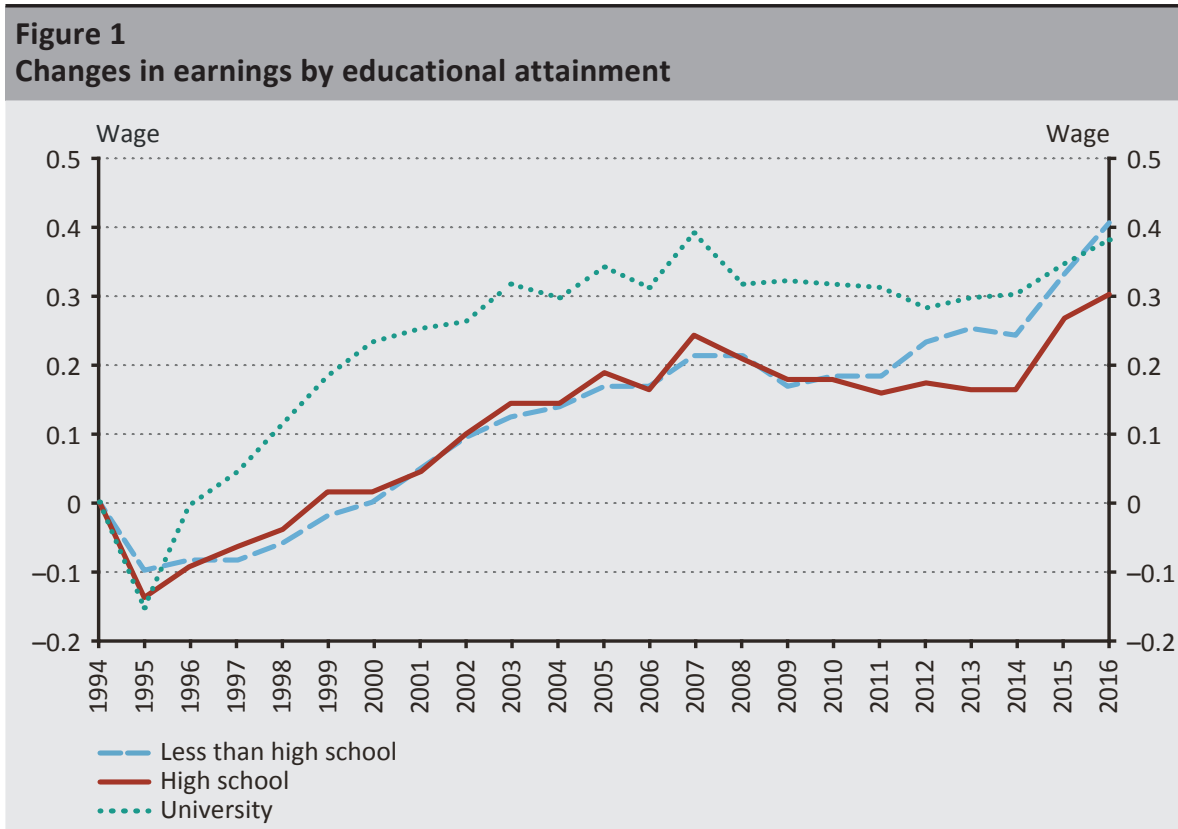

Note: $N=2,757,663$. The figure shows the change of log income relative to 1994 for workers with less than high school, high school and university education. Nominal income is deflated with the consumer price index.

\footnotetext{
${ }^{9}$ Wages are logged and their growth is measured with log difference.
} 
To summarise the development of wage differentials of workers with various levels of educational attainment, Figure 2 presents the difference in average earnings by educational attainment. One line shows the wage premium of college and university graduates relative to secondary school graduates, while the other shows the difference between secondary school graduates and unskilled workers. The university wage premium increases sharply in the first six years of the analysis and then falls or stagnates in the subsequent period. The high school wage premium shows no substantial change in the first half of the period studied and then follows a steady downward trend from 2009.

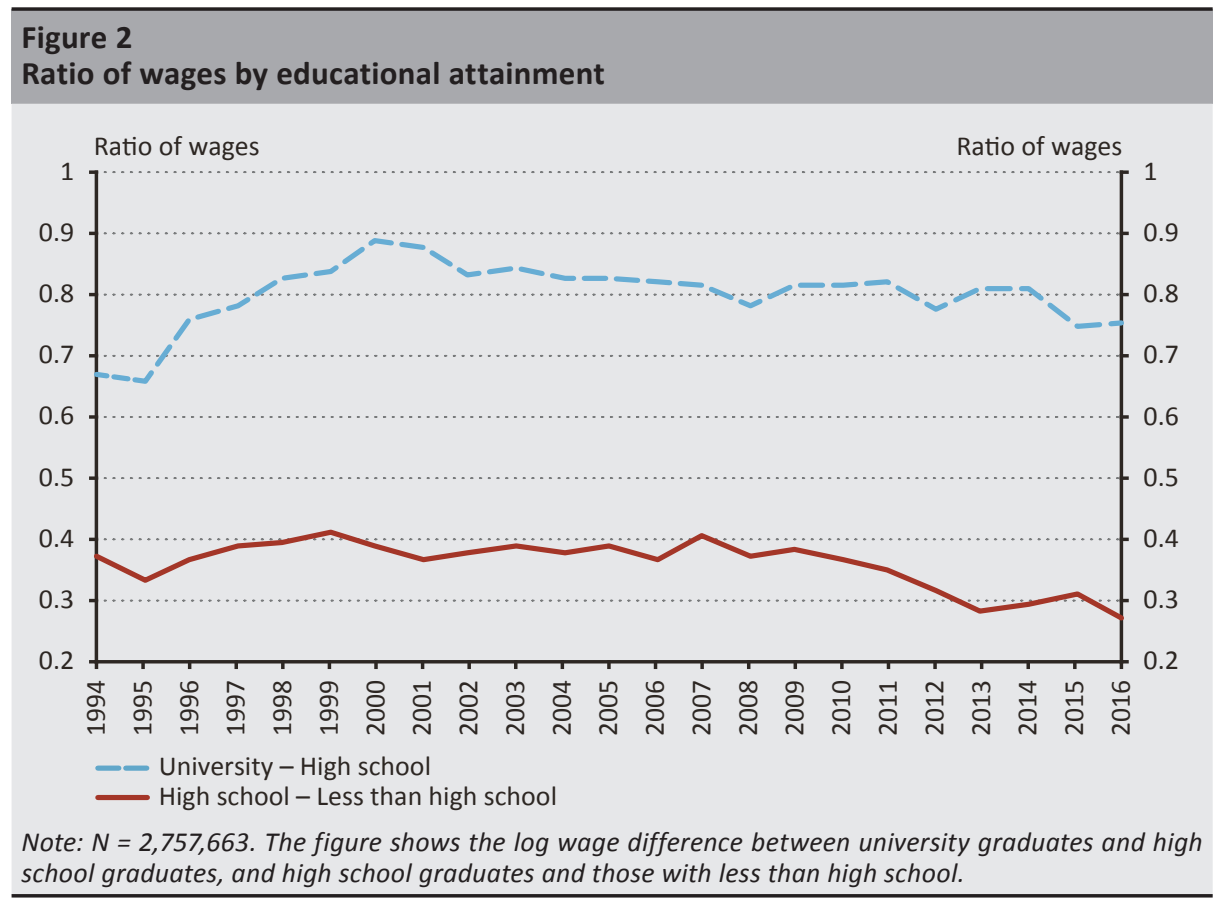

Not all university graduates perform high-skilled work, and not all low-skilled workers earn low wages. To obtain a more detailed understanding of the development of low, average and high wages in Hungary, workers are not classified based on their educational attainment but instead the wages of those in the 10th, 50th and 90th percentile of the wage distribution are tracked. Figure 3 paints a slightly different picture of wage inequality than the wage differences between the education groups. The highest wages start diverging from average and low wages at the start of the period, and maintain their advantage until 2012. Average wages follow a similar path, but their annual growth rate is lower than in the case of high wages. Low wages first drop and then gradually rise, and over the whole period have the same growth as high wages. 
Note that the wages here are gross figures, and, of course, net wage dynamics depend not only on wage levels but also on changes in the tax rates. In 2011, the rate of the personal income tax was changed, turning it from a progressive tax of 17 per cent for income of up to HUF 5 million and 32 per cent above that into a flat-rate 16-per cent tax. At the same time, the tax credit for low earners was phased out, thereby increasing the tax burden on their wages. The government also introduced the child tax allowance, which partly or completely offset the increased tax burden for low earners with children. ${ }^{10}$ As a result of the tax changes, the tax burden of low earners increased in general, while that of high earners clearly dropped. ${ }^{11}$ The steep rise in low wages at the end of the period may also partly reflect these changes. Because the net wages of high-wage workers grew substantially even if employers did not raise gross wages, employers probably mainly raised the wages of low earners where net wages declined.

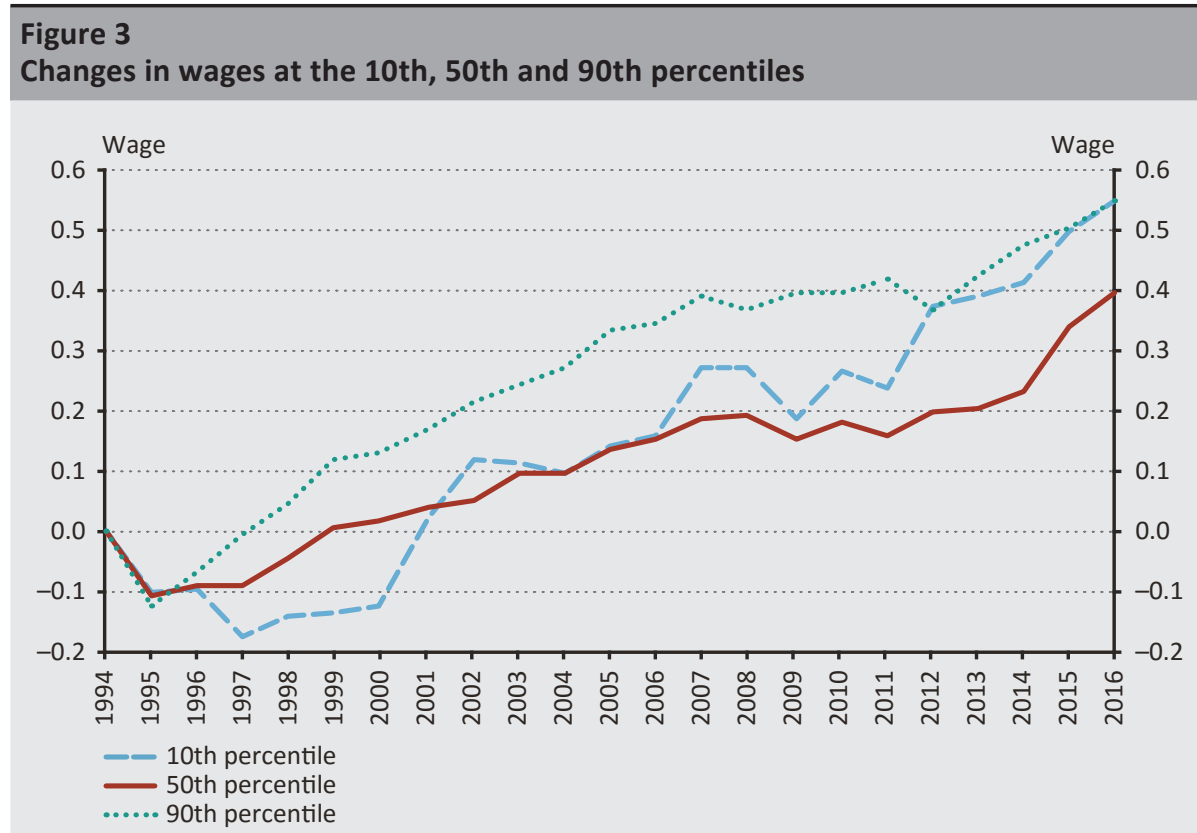

Note: $N=2,757,663$. The figure shows the change of log wages relative to 1994 for the 10 th, 50th and 90th percentile of the wage distribution. Nominal income is deflated with the consumer price index.

\footnotetext{
${ }^{10}$ In 2011, the average monthly income was HUF 213,094, with a tax burden of HUF 32,000. The tax allowance was HUF 10,000 per child for one or two children and HUF 33,000 per child for three children.

${ }^{11}$ For the extent and effects of the tax changes, see Szoboszlai et al. (2018).
} 


\subsection{Labour market polarisation}

The previous chapter analysed wage changes by worker categories. Now we turn to how much wages and employment shares changed by occupations. In line with the literature (for example Autor - Dorn 2013), occupation categories are created by 3-digit ISCO codes. Approximately one hundred different occupations are used that had the same code in 1994 and 2016. ${ }^{12}$ Figure 4 displays the occupations arranged by the median wage in 1994 (horizontal axis), while the vertical axis shows the share of the given occupation within total employment and its median income growth between 1994 and 2016. ${ }^{13}$ The figure shows that polarisation has also taken place on the Hungarian labour market. With respect to both the occupation shares and wages, medium-skilled workers lag the furthest behind, while the low- and highskilled increased their proportion as well as their wage advantage. In contrast to the United States, in Hungary the largest wage growth can be observed in the case of low-skilled labour.

The dynamics of the average wages shown in Figures 1-3 imply a change in the behaviour of the Hungarian labour market around 2000. Between 1994 and 2000, wage inequality increased (with high-earning employees earning even more and low-earners increasingly falling behind), whereas wage inequality decreased over the next 15 years, with wages of low earners catching up. We break down the period studied into two phases, and take a closer look at what happened on the labour market. Figures 5 and 6 show the changes in employment shares and wage growth for the 1990s (1994-2000) and the 2000s (2000-2016).

In the 1990s, the share of the low-skilled increased the most while the proportion of the high-skilled declined (Figure 5), and therefore labour market polarisation was not observed. Wages became polarised to the extent that in the lowest-paying occupations wages rose at a slightly higher rate than around the 20th percentile; nevertheless, the most important phenomenon was that wages started increasing linearly from the 20th percentile upwards, proportional to the initial wage. ${ }^{14}$ This behaviour is similar to the period between 1980 and 1990 in the United States when income increased linearly with education (Katz - Murphy 1992, Autor et al. 2006). This is described in the Tinbergen model, which was presented in the section 2.1.

\footnotetext{
${ }^{12}$ Examples of such occupations are "heads of production units", "financial and accounting professions", "food industry occupations", "cleaners".

${ }^{13}$ The figure was prepared using locally weighted regression.

${ }^{14}$ Kertesi and Köllö (2002) reach similar conclusions with respect to wage growth in the 1990s.
} 


\section{Figure 4}

Change in employment shares and wages, 1994-2016
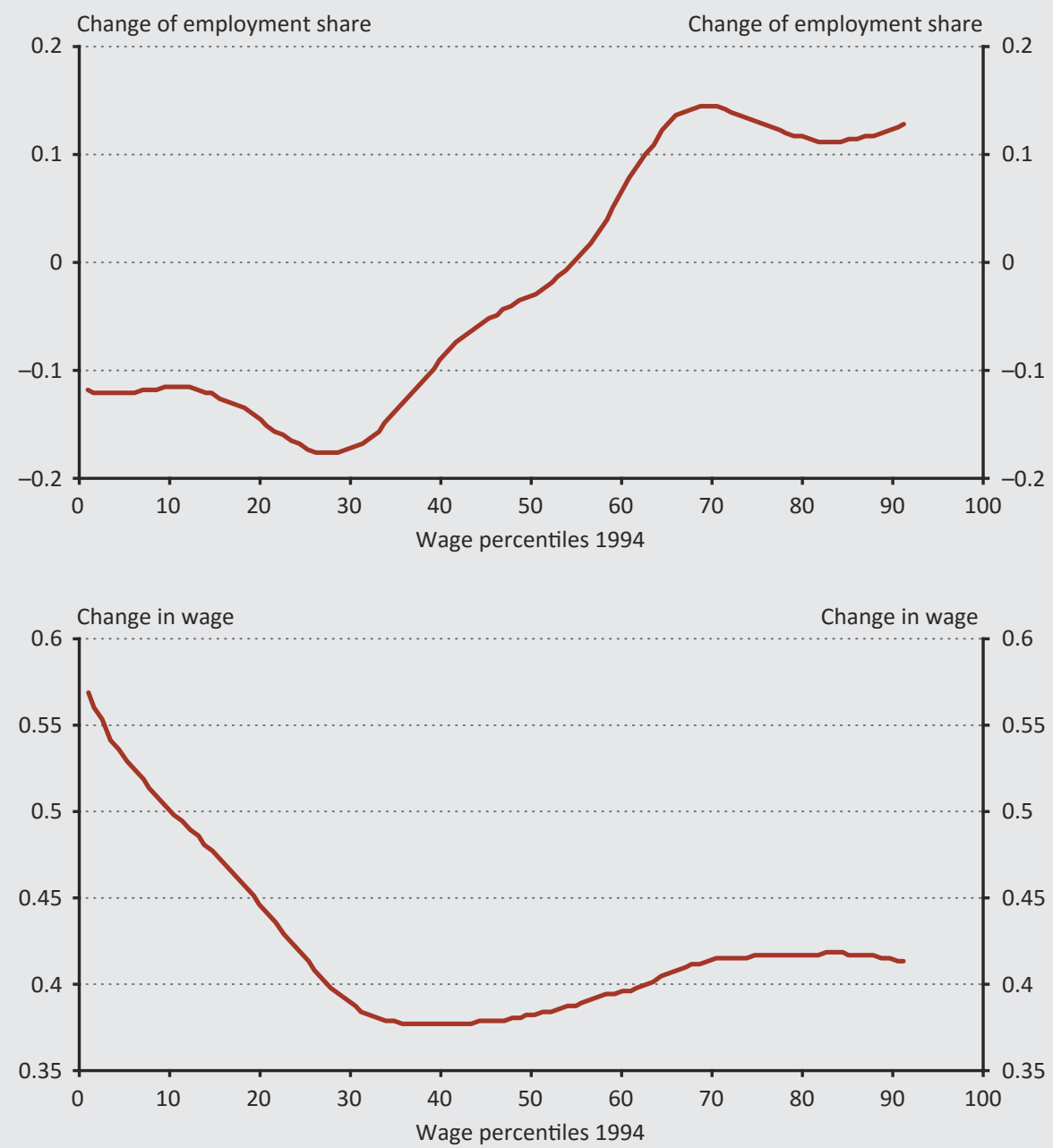

Note: $N=2,757,663$. The upper panel shows the change in the share of occupations in total employment between 1994 and 2016, as a function of where the average median wage of the occupations fell within the 1994 wage distribution. The lower panel shows the average wage growth of occupations between 1994 and 2016, as a function of where the average median wage of the occupations fell within the 1994 wage distribution. Occupations are defined at the level of 3-digit ISCO codes. Log wages are used. The figure was prepared using locally weighted regression. 


\section{Figure 5 \\ Change in employment shares and wages, 1994-2000}
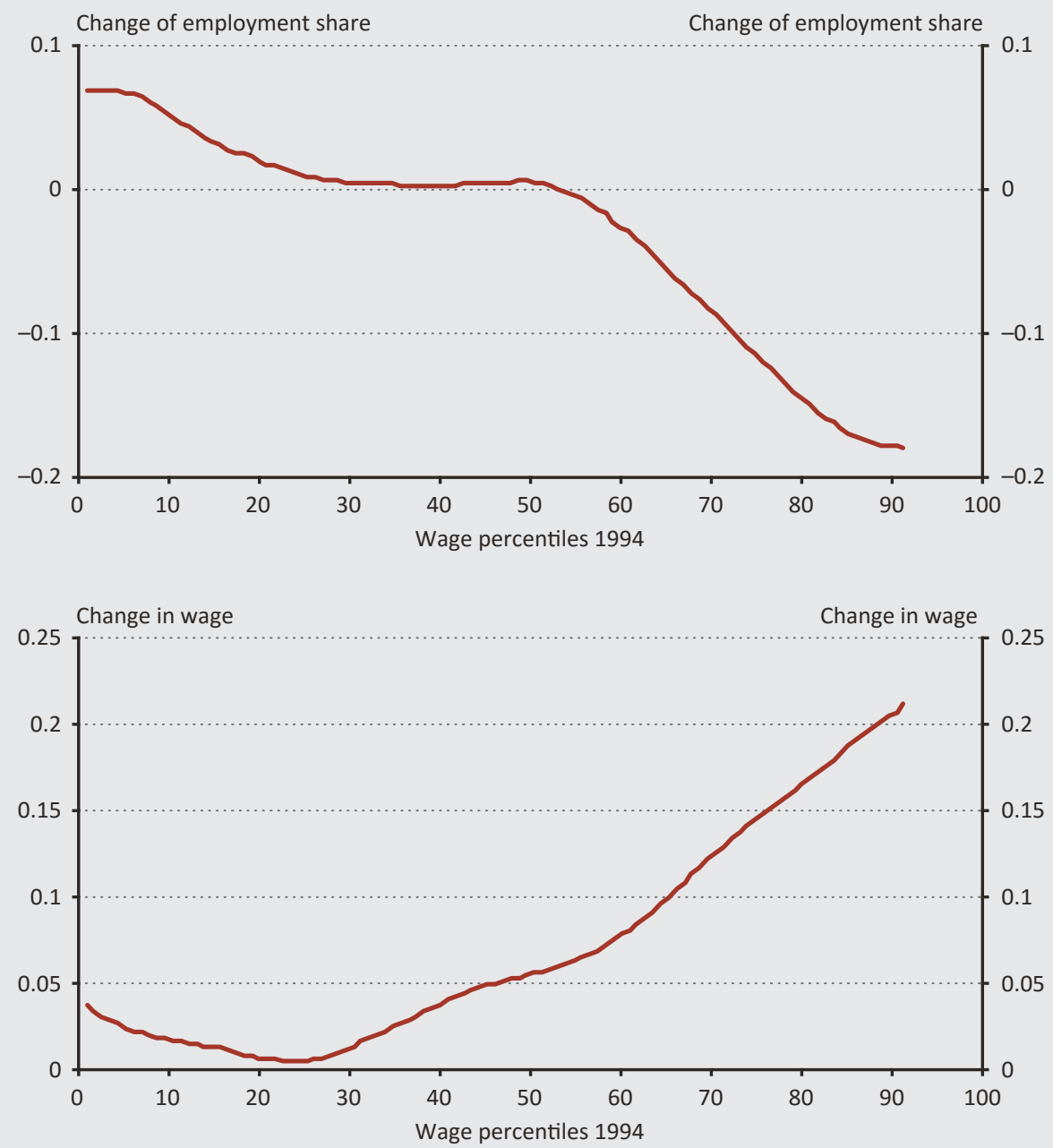

Note: $N=2,757,663$. The upper panel shows the change in the share of occupations in total employment between 1994 and 2000, as a function of where the average median wage of the occupations fell within the 1994 wage distribution. The lower panel shows the average wage growth of occupations between 1994 and 2000, as a function of where the average median wage of the occupations fell within the 1994 wage distribution. Occupations are defined at the level of 3-digit ISCO codes. Log wages are used. The figure was prepared using locally weighted regression. 
One surprising aspect in the figure is that the share of the high-skilled workers declines while their wages increase. Commander and Köllö (2008) examine the period 1997-2000 and find that the proportion of the low-skilled drops. If Figure 5 were prepared for this period, it would yield similar results. Therefore, the lowskilled gained prominence before 1997, and a likely explanation for this can be found in business cycles. According to Nagy (2000), the unemployment rate peaked in 1993 (at 11.9 per cent). It steadily decreased over the subsequent years, standing at merely 7 per cent in 1999. However, the average unemployment rate conceals huge differences in terms of educational attainment. For the high-skilled, it was very low in 1993 (for example for males it was 3 per cent), and it declined by only 1.3 percentage points. By contrast, it tumbled from 15 per cent to 8.3 per cent for those with vocational training. The economic crisis that emerged in the early 1990s, just like the subsequent recovery, affected the chances of the low-skilled on the labour market much more, and Figure 5 presumably reflects this. The highskilled enjoyed almost full employment even at the trough of the business cycle, and growth for this group was probably halted by their supply: much more highskilled workers were needed during the recovery than there were in Hungary, and the intense demand for such experts boosted their wages. However, there were many unemployed among low-skilled workers who could be employed without significantly increasing their wages.

Between 2000 and 2016, the wage and employment shares changed by occupation very differently than in the 1990s (Figure 6): the labour market became highly polarised, i.e. the share of both low- and high-skilled jobs increased dramatically at the expense of average earners. However, the behaviour of wages was completely different from that seen in the US, because their growth rate was inversely proportional to initial wages. The lower the initial wage, the higher the wage growth. ${ }^{15}$ Therefore the Hungarian labour market became polarised without the polarisation of wages, and inequality declined at the same time. ${ }^{16}$ The next subchapter seeks to provide an explanation for this behaviour.

\footnotetext{
${ }^{15}$ Underdeclared work may paint a more varied picture, as with that employees are officially paid the minimum wage while in reality their earnings are higher. Since the minimum wage was low at the beginning of the period, the income of low-earning employees is likely to have grown less in the period relative to high-skilled and high-earning employees, who were not affected, even indirectly, by changes in the minimum wage.

${ }^{16}$ One possible issue might be that the Great Recession was in the middle of the period under review, and Figure 6 may reflect the effects of that. Nevertheless, this is not very likely. Köllö (2011) analyses the shortterm impact of the crisis and finds that it did not affect inequality much.
} 


\section{Figure 6 \\ Change in employment shares and wages, 2000-2016}
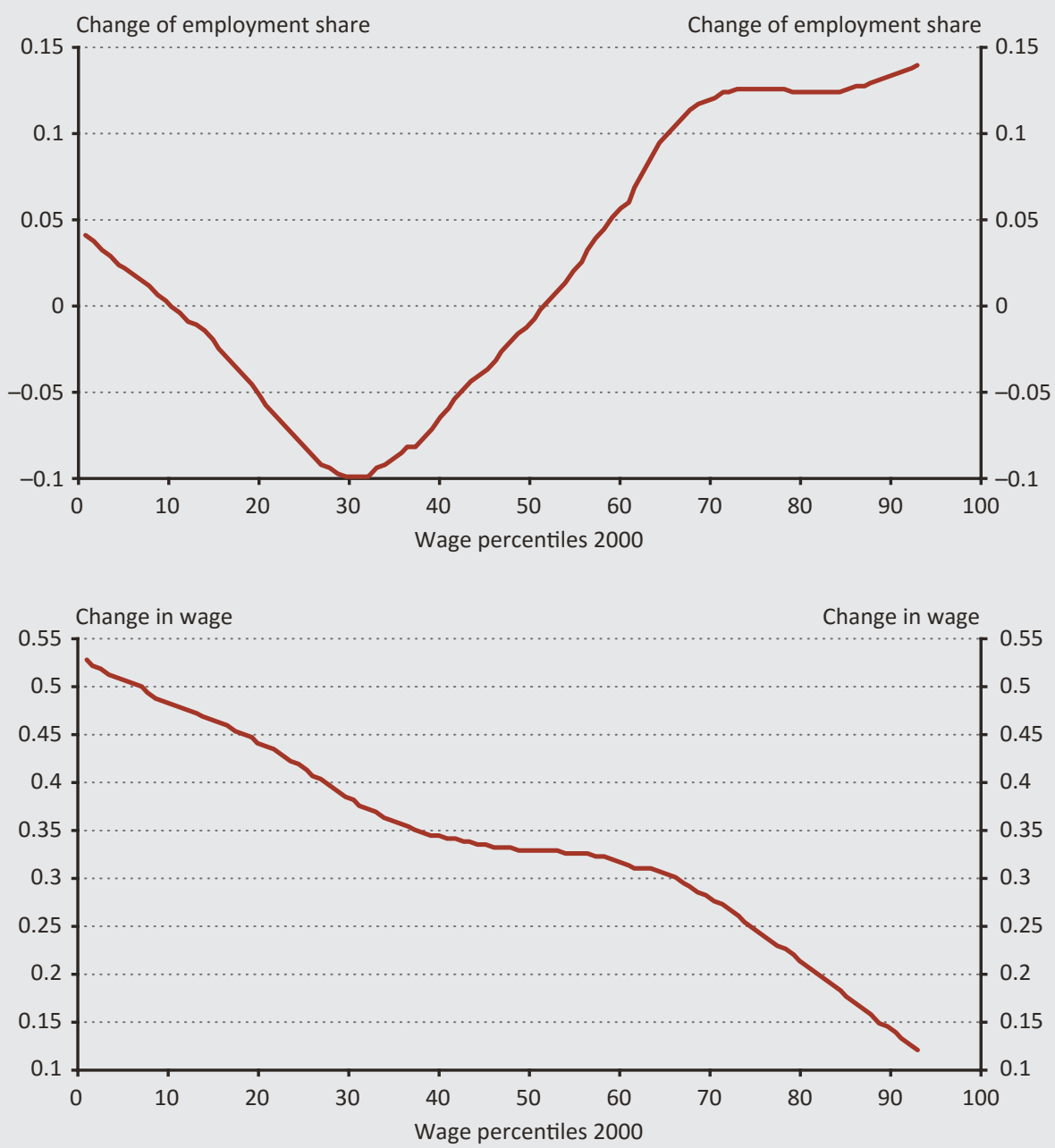

Note: $N=2,757,663$. The upper panel shows the change in the share of occupations in total employment between 2000 and 2016, as a function of where the average median wage of the occupations fell within the 2000 wage distribution. The lower panel shows the average wage growth of occupations between 2000 and 2016, as a function of where the average median wage of the occupations fell within the 2000 wage distribution. Occupations are defined at the level of 3-digit ISCO codes. Log wages are used. The figure was prepared using locally weighted regression. 
Finally, let us consider how the presence of the large occupational groups changed on the labour market. The green bars in Figure 7 show the changes in employment shares in the 1990s, while the blue bars show the changes in the 2000s among service workers, skilled labourers, retail staff, office staff, high-skilled occupations and managers. ${ }^{17}$ In the 1990s, the share of skilled labourers is shown to have increased considerably, whereas the share of office staff and managers decreased. This coincides with the appearance of large multinational companies in Hungary, a majority of which operate in manufacturing. Conversely, in 2000-2016 there was a major increase in the share of high-skilled and service occupations, whereas that of skilled labourers dropped, which is consistent with the polarisation of the labour market.

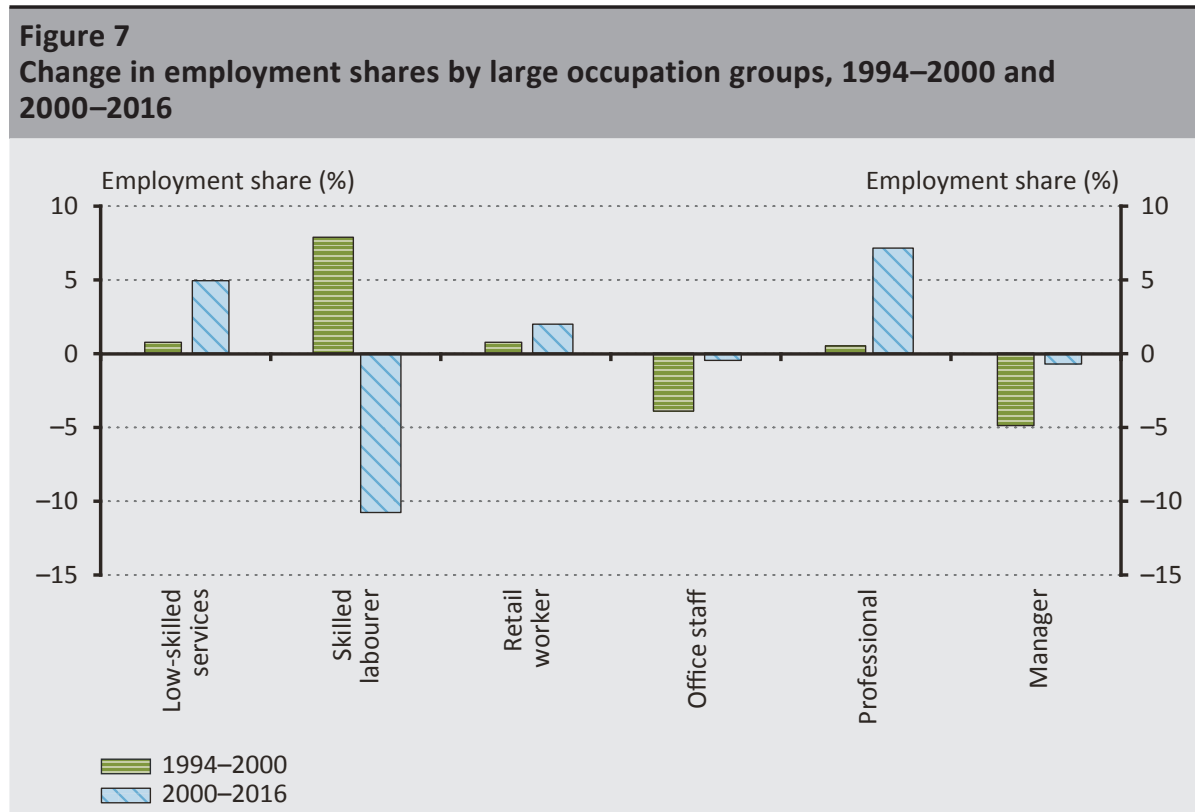

Note: $N=2,757,663$. The figure shows the change in the share of large occupation groups on the labour market in 1994-2000 and 2000-2016. The occupation groups comprise the following 2-digit ISCO codes: low-skilled services $(90,84,52-53)$, skilled labourer $(70,81,82,83)$; retail worker (51-52), office staff (40), professional $(20,30)$, manager (10).

Polarisation of employment, therefore, took place in the 2000s, but it was not coupled with wage polarization, as wage growth was inversely proportional to the initial wage. Hungarian companies used the new production technologies, which transformed the composition of occupations: the share of routine jobs diminished. However, wages did not reflect the change in demand. In the following, an explanation is sought for why labour market polarisation occurred only in employment shares and not at the level of wages.

\footnotetext{
${ }^{17}$ The classification of occupation groups by ISCO codes is shown in the notes to the figure.
} 
There are two possible mechanisms that influenced wage inequality after 2000. One is the rise in the minimum wage, while the other is the expansion in higher education. As can be seen in Figure 8, the minimum wage was low relative to average earnings in the 1990s (Hungarian Central Statistical Office, website). To address this, the government doubled the minimum wage in 2001-2002, after which it subsequently fell again relative to the average wage. However, it was raised again substantially between 2009 and $2012 .{ }^{18}$ Comparing the changes in the minimum wage to wage growth in Figures 1 and 2, it is clear that the wages of the lowest earners increased significantly in these two periods. To see how much wages changed in the period when the minimum wage did not increase significantly, a wage polarisation figure is prepared for the period when the minimum wage did not rise (2002-2011). The wage of low-paying occupations lagged behind averageearning jobs in that period (Figure 9). Therefore, the considerable increase in the minimum wage contributed to the fact that earnings in low-wage occupations grew more than earnings in other jobs.

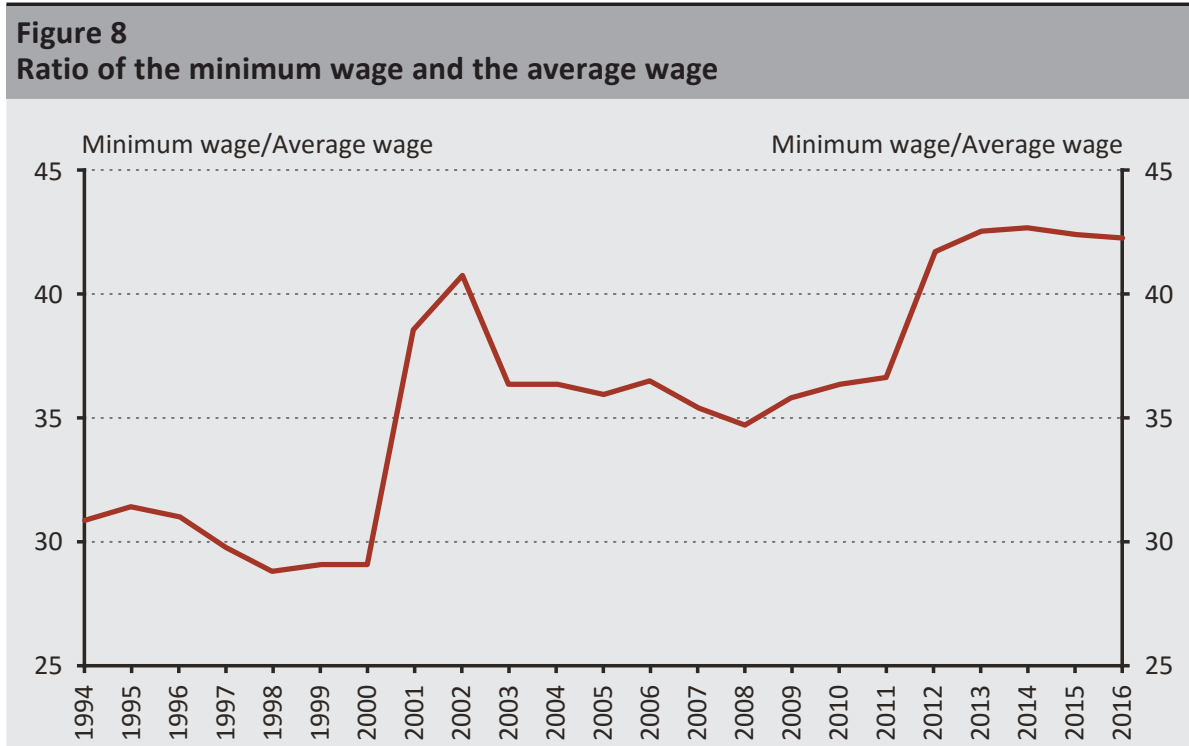

Note: The figure shows the proportion of the minimum wage to gross average earnings in percentage terms.

\footnotetext{
${ }^{18}$ The large number of studies that analyse the impact of the minimum wage on employment of the low-skilled find mostly zero or a small negative impact (Card-Krueger 1995), although some authors believe that the negative effects are not negligible (Neumark et al. 2014). In their analysis of the minimum wage increase of 2001-2002 in Hungary, Harasztosi and Lindner (2017) found no negative employment effects. The same change was also analysed by Kertesi and Köllö (2003), who, however, did find substantial short-term effects.
} 


\section{Figure 9}

Wage growth, 2002-2011

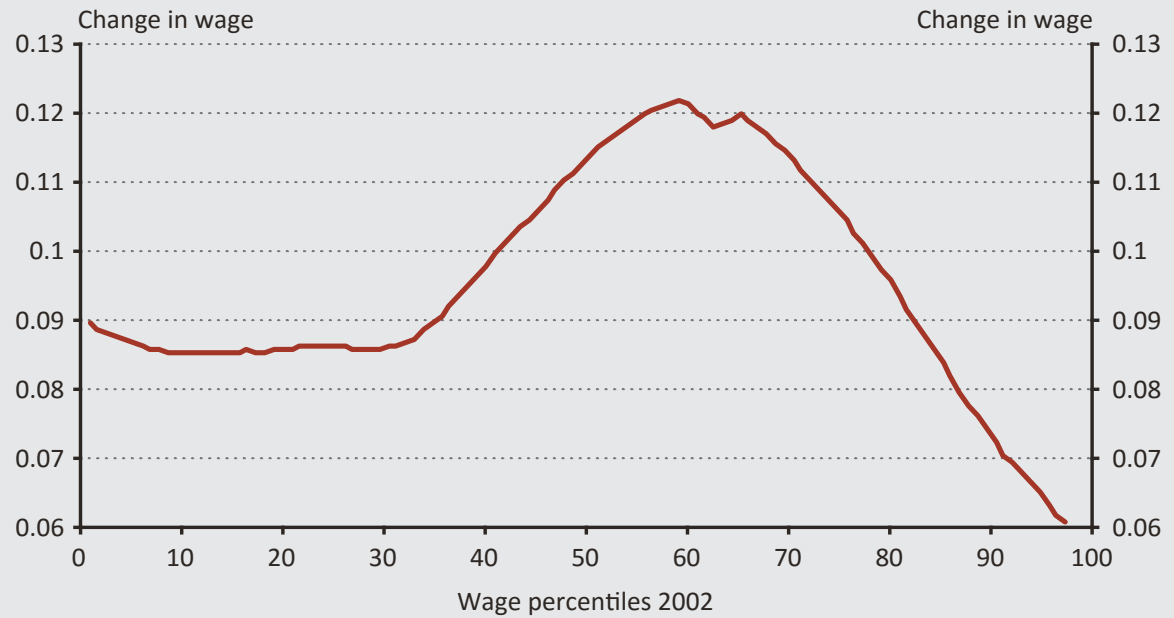

Note: $N=2,757,663$. The figure shows the average wage growth of occupations between 2002 and 2011, as a function of where the average median wage of the occupations fell within the 2002 wage distribution. Occupations are defined at the level of 3-digit ISCO codes. Log wages are used. The figure was prepared using locally weighted regression.

The other process reduced the growth rate of high wages. The expansion in higher education in Hungary took place at a very rapid rate and radically changed the share of workers on the labour market with a college or university degree. Figure 10 shows the proportion of graduates on the labour market, which was 9-10 per cent at the beginning of the period studied. This did not change much in the 1990s, but the share of graduates doubled after 2000. According to a market model, relative wage growth (in this case the wage advantage of skilled workers relative to the unskilled) is determined by the size of supply and demand. In the following, we formalise this based on the methodology of Autor et al. (1998). 


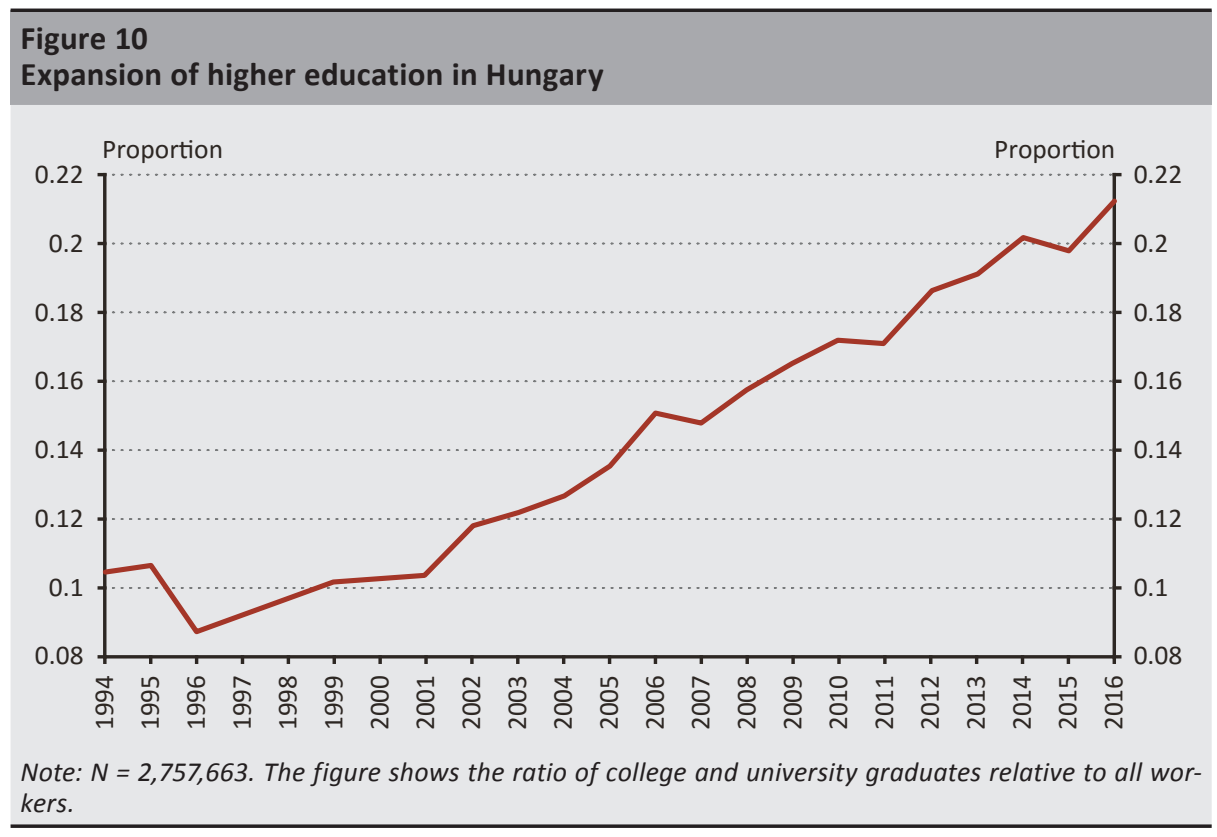

Two types of workers are used: the skilled (measured by the number of graduates) and the unskilled (those with at most a secondary school diploma). We note their numbers by $N_{1}$ and $N_{2}$, and their average wage by $w_{1}$ and $w_{2}$. The relative supply of graduates is:

$$
\mathrm{S}=\log \left(\mathrm{N}_{1} / \mathrm{N}_{2}\right) .
$$

To quantify relative demand, we assume a CES global production function, and the two types of workers produce the final product $\mathrm{Q}$ :

$$
Q=\left[\alpha\left(A_{1} N_{1}\right)^{(\sigma-1) / \sigma}+(1-\alpha)\left(A_{2} N_{2}\right)^{(\sigma-1) / \sigma}\right]^{\sigma /(\sigma-1)},
$$

where $\alpha, A_{1}, A_{2}$ are the parameters of the technology used, and $\sigma$ is the elasticity of substitution between skilled and unskilled workers. If technological progress does not change the productivity of the two groups of workers, $A_{1} / A_{2}$ and $\alpha$ are stable. If the productivity of skilled workers increases relative to the unskilled, $A_{1} /$ $\mathrm{A}_{2}$ or $\alpha$ rises.

Assuming that workers' wage equals their marginal product, the derivative of the production function with respect to $N_{1}$ and $N_{2}$ yields the relative wage of skilled and unskilled workers:

$$
\log \left(w_{1} / w_{2}\right)=1 / \sigma\left[D-\log \left(N_{1} / N_{2}\right)\right],
$$


where $\log \left(\mathrm{N}_{1} / \mathrm{N}_{2}\right)$ equals the relative supply of the two worker categories, and $D$ is a measure of relative demand, which depends solely on the technological parameters $A_{1}, A_{2}, \sigma$ and $\alpha$. The greater $D$ is, the larger companies' relative demand for skilled workers. Equation (5) can be used to express relative demand:

$$
D=\log \left[\left(w_{1} N_{1}\right) /\left(w_{2} N_{2}\right)\right]+(\sigma-1) \log \left[w_{1} / w_{2}\right] \text {. }
$$

Both the supply in Expression (3) and the demand determined in Expression (6) can be calculated based on the data. In line with the literature, $\sigma$ is attributed a value of 1.4, but similar results are derived for other values (e.g. 1 and 2). Table 2 shows the calculated relative wages as well as the changes in relative supply and demand for five-year periods as well as the 1990s and the 2000s. ${ }^{19}$ The relative supply of skilled workers increased by merely 4.1 per cent relative to those with at most a secondary school diploma between 1995 and 2000. However, this trend changed in the 2000s when the students that enrolled to colleges and universities after the political transition entered the labour market. Relative supply increased by $33 \mathrm{log}$ points in the next five-year period. Between 2005 and 2010, the growth rate of relative supply diminished somewhat, to 25 log points, and finally, in the last fiveyear period, it declined further, to 22 log points.

Demand followed a different path. In the 1990s, the relative demand for skilled workers increased dramatically (by 31 log points), however, this rate steadily declined in 2000-2015. It increased by 22-24 log points in the first two periods, and by 11 in the last.

The comparison of the relative demand and supply shows that relative demand grew much more than relative supply in the 1990s. However, after the turn of the millennium, the further expansion of demand could not offset the tremendous growth in supply, which is reflected in wage dynamics. The graduate wage premium spiked between 1995 and 2000 (by 19 log points), but it diminished steadily in the subsequent period, mostly when relative supply increased.

The table also presents relative demand and supply figures for the two large periods analysed in the previous section. Relative supply stagnated between 1995 and 2000, relative demand increased sharply in favour of skilled workers, and the relative wage expanded substantially. In 2000-2015, the opposite occurred. The large supply growth could not be offset by the increasing demand, which led to a 17-log point drop in the graduate wage premium. Over the whole period, the wage premium increased by merely 2 log points.

${ }^{19}$ The annual data exhibit large volatility, and therefore the amounts in the table equal the average of the given year and years directly preceding and following it ("2015" indicates the average of 2014-2016). 


\begin{tabular}{|c|c|c|c|}
\hline \multicolumn{4}{|c|}{$\begin{array}{l}\text { Table } 2 \\
\text { Changes in relative supply, relative demand and relative wages }\end{array}$} \\
\hline Period & Relative supply & Relative demand & Relative wage \\
\hline $1995-2000$ & 0.041 & 0.309 & 0.191 \\
\hline $2000-2005$ & 0.325 & 0.240 & -0.061 \\
\hline 2005-2010 & 0.250 & 0.217 & -0.024 \\
\hline 2010-2015 & 0.227 & 0.105 & -0.087 \\
\hline 2000-2015 & 0.803 & 0.562 & -0.172 \\
\hline 1995-2015 & 0.840 & 0.872 & 0.019 \\
\hline
\end{tabular}

Note: $N=2,757,663$. The table presents the change in the relative supply, demand and wage difference between graduates and those working with at most a secondary school diploma for the period shown in Column 1. Relative supply equals the log difference between the number of skilled and unskilled workers. Relative demand follows from the maximisation of a CES production function, where the inputs are the number of skilled and unskilled workers (see Expression [6] in the text). The wage difference equals the log difference between the average wage of skilled and unskilled workers. The annual amounts equal the average of the given year and the years directly preceding and following it.

\section{Conclusions}

This study analysed wage inequality in Hungary over the past 20 years. In the 1990s, Hungary mirrored the labour market wage changes in the United States ten years earlier. This changed in the next decade when the share of the various occupations varied as in developed countries: labour market polarisation occurred, i.e. the share of low-skilled and high-skilled jobs increased, while the proportion of mediumskilled jobs dropped. However, wages did not become polarised. The higher the wages in an occupation in 2000, the less they increased in the next 15 years. This can be attributed to two factors: first, the government raised the minimum wage twice during the period, thereby pushing up the earnings of the low-skilled. Second, the expansion in higher education in the 1990s, which bore fruit around 2000, increased the share of college and university graduates within the labour force, which had a negative impact on the graduate wage premium. As a result of the substantial increase in inequality in the 1990s and the balancing developments of the 2000s, wage inequality was unchanged over the whole period: in 2016 the graduate wage premium was close to what it had been in 1994. 


\section{References}

Acemoglu, D. - Autor, D. (2011): Skills, Tasks and Technologies: Implications for Employment and Earnings. In: Card, D. - Ashenfelter, O. (eds.): Handbook of Labor Economics. North Holland: Elsevier: 1045-1170. https://doi.org/10.1016/S0169-7218(11)02410-5

Acemoglu, D. - Restrepo, P. (2016): Robots and Jobs: Evidence from the U.S. Labor Markets. NBER Working Paper No. 23285.

Arntz, M. - Gregory, T. - Zierahn, U. (2016): The Risk of Automation for Jobs in OECD Countries. OECD Social, Employment and Migration Working Papers, No. 189. https://doi.org/10.1787/5jlz9h56dvq7-en

Autor, D. - Dorn, D. (2013): The Growth of Low-Skill Service Jobs and the Polarization of the U.S. Labor Market. American Economic Review, 103(5): 1553-1597. https://doi.org/10.1257/aer.103.5.1553

Autor, D. - Dorn, D. - Hanson, G. (2013): The China Syndrome: Local Labor Market Effects of Import Competition in the United States. American Economic Review, 103(6): 2121-2168. https://doi.org/10.1257/aer.103.6.2121

Autor, D. - Katz, L. - Kearney, M. (2006): The Polarization of the US Labor Market. American Economic Review Papers and Proceedings, 96(2): 189-194. https://doi.org/10.1257/000282806777212620

Autor, D. - Katz, L. - Krueger, A. (1998): Computing Inequality: Have Computers Changed the Labor Market? Quarterly Journal of Economics, 113(4): 1169-1213. https://doi.org/10.1162/003355398555874

Baldwin, R. (2016), The Great Convergence: Information Technology and the New Globalization. Cambridge, Massachusetts: Belknap University Press of Harvard University Press.

Brynjolfsson, E. - McAfee, A. (2014): The Second Machine Age. Work, Progress, and Prosperity in a Time of Brilliant Technologies. United States: W.W. Norton \& Company, Inc.

Card, D. - DiNardo, J. (2002): Skill-Biased Technological Change and Rising Wage Inequality: Some Problems and Puzzles. Journal of Labor Economics, 20(4): 733-783. https://doi.org/10.1086/342055

Card, D. - Krueger, A. (1995), Myth and Measurement: The New Economics of the Minimum Wage. Princeton, New Jersey: Princeton University Press.

Commander, S. - Köllö, J. (2008): The Changing Demand for Skills. Economics of Transition, 16(2): 199-221. https://doi.org/10.1111/j.1468-0351.2008.00303.x

Goldin, C. - Katz, L. (2008): The Race between Education and Technology. Cambridge, Massachusetts: The Belknap Press of Harvard University Press. 
Goos, M. - Manning, A. - Salamons, A. (2009): Job Polarization in Europe. American Economic Review Papers and Proceedings, 99(2): 58-63. https://doi.org/10.1257/aer.99.2.58

Harasztosi, P. - Lindner, A. (2017): Who Pays for the Minimum Wage? Mimeo.

Hungarian Central Statistical Office (website): http://www.ksh.hu/docs/hun/xstadat/xstadat_ eves/i_qli041.html

Katz, L. - Autor, D. (1999): Changes in the Wage Structure and Earnings Inequality. In: Card, D. - Ashenfelter, O. (eds.): Handbook of Labor Economics. North Holland: Elsevier.

Katz, L. - Murphy, K. (1992): Changes in Relative Wages, 1963-1987: Supply and Demand Factors. Quarterly Journal of Economics, 107(1): 35-78. https://doi.org/10.2307/2118323

Kertesi, G. - Köllö, J. (2002): Economic Transformation and the Revaluation of Human Capital - Hungary. 1986-1999. In: de Grip, A. - van Loo, J. - Mayhew, K. (eds.): The Economics of Skills Obsolescence (Research in Labor Economics, Volume 21). Emerald Group Publishing Limited.

Kertesi, G. - Köllö, J. (2003): Fighting "Low Equilibria" by Doubling the Minimum Wage? Hungary's Experiment. IZA Discussion Paper No. 970.

Köllő, J. (2011): Hungary: Crisis Coupled with a Fiscal Squeeze - Effects on Inequality. In: Vaughan-Whitehead, D. (ed.): Work Inequalities in the Crisis. Evidence from Europe. Cheltenham and Northampton: Edward Elgar.

Magyar Nemzeti Bank (2017): Growth Report. Budapest: Magyar Nemzeti Bank. https://www.mnb.hu/letoltes/novekedesi-jelentes-2017-en-web.pdf

Nagy, Gy. (2000): Munkanélküliség a kilencvenes években (Unemployment in the 1990s). In: Kolosi, T. - Tóth, I.Gy. - Vukovich, Gy. (eds.): Társadalmi Riport 2000. Budapest: TÁRKI.

Neumark, D. - Salas, I. - Wascher, W. (2014): Revisiting the Minimum Wage-Employment Debate: Throwing Out the Baby with the Bathwater? Industrial and Labor Relations Review, 67(Supplement): 608-648. https://doi.org/10.1177/00197939140670S307

Szoboszlai, M. - Bögöthy, Z. - Mosberger, P. - Berta, D. (2018): A 2010-2017 közötti adó- és transzferváltozások elemzése mikroszimulációs modellel (Analysis of the changes in the tax and transfer system in 2010-2017 using a microsimulation model). MNB Occasional Papers 135.

Tinbergen, J. (1974): Substitution of Graduate by Other Labor. Kyklos, 27(2): 217-226. https:// doi.org/10.1111/j.1467-6435.1974.tb01903.x

World Bank (2016): World Development Report: Digital Dividends. Washington, DC: The World Bank. 